\title{
Seismic anisotropy in Eastern Tibet from shear wave splitting reveals changes in lithospheric deformation
}

\author{
Einat Lev*, Maureen D. Long, Rob D. van der Hilst \\ Department of Earth, Atmospheric, and Planetary Sciences, Massachusetts Institute of Technology, \\ 77 Massachusetts Avenue, Cambridge, MA 02139, USA
}

Received 25 April 2006; received in revised form 9 August 2006; accepted 5 September 2006

Available online 17 October 2006

Editor: C.P. Jaupart

\begin{abstract}
Knowledge about seismic anisotropy can provide important insight into the deformation of the crust and upper mantle beneath tectonically active regions. Here we focus on the southeastern part of the Tibetan plateau, in Sichuan and Yunnan provinces, SW China. We measured shear wave splitting of core-refracted phases (SKS and SKKS) at a temporary array of 25 IRIS-PASSCAL stations. We calculated splitting parameters using a multi-channel and a single-record cross-correlation method. Multiple layers of anisotropy cannot be ruled out but are not required by the data. A Fresnel zone analysis suggests that the shallow mantle (between 60 and $160 \mathrm{~km} \mathrm{depth)}$ is the most likely source of anisotropy. The polarization directions reveal a pronounced transition from primarily north-south in the north (Sichuan) to mostly east-west orientations in the south (Yunnan). In the southern part of the study region, that is, south of $\sim 26^{\circ} \mathrm{N}$, the fast polarization directions do not correlate well with known surface features and geodetic estimates of the crustal displacement fields. Whereas GPS campaigns provide evidence suggesting north-south crustal flow across the Red River Fault, the pattern of anisotropy argues against such flow in the upper mantle. These observations support models that allow differential movement of upper crust relative to lithospheric mantle. In the northern part of the study region the relationships are more ambiguous and coherent deformation of the crust and mantle lithosphere cannot be excluded. The interpretation of the shear wave splitting results is non-unique, but we suggest that the observed N-S transition reflects a fundamental change in deformation regime across our study region. It may be related to lateral variations in lithospheric rheology, or may mark a transition from the direct impact of the continental collision to dominance of the far-field strain field associated with regional subduction processes. Understanding the nature of the lateral change in deformation regime may prove critical for our understanding the geotectonic evolution of (eastern) Tibet.
\end{abstract}

(C) 2006 Elsevier B.V. All rights reserved.

Keywords: continental collision; shear wave splitting; Tibetan plateau

\section{Introduction}

The Tibetan plateau is the result of the collision between India and Eurasia, which started approximately

\footnotetext{
* Corresponding author. Tel.: +1 617253 8872; fax: +1 6172531699.

E-mail address: einatlev@mit.edu (E. Lev).
}

50 million years ago and which has produced at least $2000 \mathrm{~km}$ of convergence. Since the collision the Tibetan crust has doubled in thickness, and the plateau surface has been elevated to $4-5 \mathrm{~km}$ [1].

Distinctly different mechanisms have been suggested to explain the evolution of the Tibetan plateau and adjacent regions. Molnar and Tapponnier [2], and many later studies, place significant relative motion along 
major strike-slip faults to facilitate eastward extrusion of crustal material out of Tibet. Other interpretations, in contrast, focus on modes of crustal thickening. England and Houseman [3] used numerical models of a thick viscous sheet, in which the Asian crust is thickened by collision of an indentor. These models predict significant shortening in the eastern margin of Tibet. However, despite the high elevation in the area, no evidence for significant upper crustal shortening has been found [4]. This led researchers to develop a model which invokes ductile flow of the lower crust and mechanical decoupling of the upper crust and mantle [5]. According to this model, which is supported by geodetic studies (e.g., $[6,7]$ - see Fig. 1), material extruded from Tibet flows clockwise around the eastern Himalayan syntaxis into southeastern Tibet and Yunnan province, and across the Red River Fault zone.
Because pervasive rock deformation may produce anisotropy on the scale of seismic wavelengths [e.g., 810] we may be able to discriminate between competing tectonic models by analyzing the style of seismic anisotropy that they would produce. For example, ductile flow in the lower crust requires that it is weak, and the implied possibility of differential behavior and motion of upper crust and lithospheric mantle may produce patterns of mantle anisotropy that have a complex relationship to surface structures. In contrast, a crust and mantle that are strongly coupled would deform coherently so that the inferred anisotropy is likely to be more consistent with deformation patterns observed at the surface.

Seismic anisotropy can be probed using a variety of seismological tools, including surface wave analysis [e.g. 11,12], anisotropic receiver functions [13], azimuthal variations in Pn travel times [e.g. 14,15], and

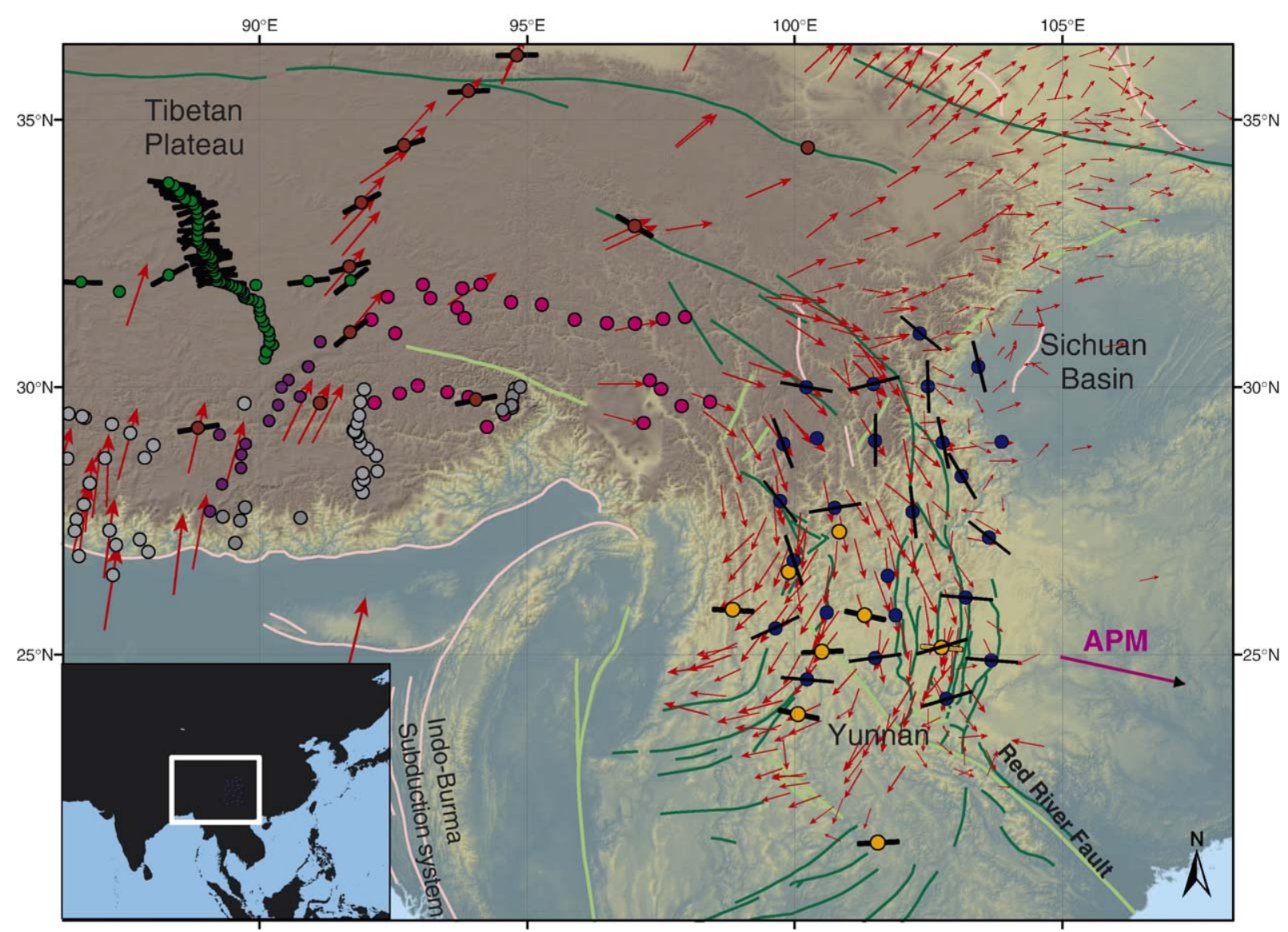

Fig. 1. Location of the seismic stations used in this study (dark blue dots) and the fast polarization direction estimated for them. The background shows the topography of East Asia and the regional faults (dark green — left-lateral strike-slip faults, light green — right-lateral strike slip faults, pink — thrust faults). APM = the local absolute plate motion direction by NUVEL-1 [44]. Previous shear waves splitting results are also shown: green dots — [48]; red dots — [17]; orange dots and orange line at station KMI — [23]. Pink dots depict the location of the seismic stations used by [24]. Red arrows denote geodetically measured surface velocities relative to the South China block [after 6,7]. 
shear wave splitting [e.g. 16]. Shear wave splitting is an unambiguous indicator of anisotropy, but it is often difficult to determine the depth of the anisotropy that produces the observed signals.

Several seismic studies performed on or near the Tibetan plateau have attempted to determine the level of mechanical coupling between the crust and the mantle. McNamara et al. [17] found systematic variations of anisotropy from the center of the plateau northward that were in agreement with surface geologic features. They concluded that the deformation resulting from the continental collision extends well into the upper mantle. Holt et al. [18] compared results from shear wave splitting studies with models of finite mantle strain in Tibet. Based on the alignment of the fast directions of shear wave polarization with the direction of shear in the crust, they inferred that the present day direction of shear in the mantle is similar to that in the crust. A similar conclusion was reached by Griot et al. [19], who found a strong correlation between azimuthal seismic anisotropy inferred from surface waves and the anisotropy predicted from a "homogeneous" model, in which the crust and the mantle deform coherently to a depth of at least $200 \mathrm{~km}$. In contrast, using anisotropy of the surface waves recorded at the INDEPTH-III array, Shapiro et al. [20] found evidence for thinning of and flow in the lower crust in Tibet. Sherrington et al. [21] and Ozacar and Zandt [22] used receiver functions to study crustal anisotropy in Tibet, and both concluded that the middle to lower crust in Tibet is anisotropic and likely to be deforming ductily. Sherrington et al. [21] interpreted the difference between the crustal anisotropy they observe and reported mantle anisotropy to indicate distinct deformation of the crust and mantle. Recently, Flesch et al. [23] combined shear wave splitting measurements and geodynamical modeling to argue that the crust and the upper mantle are coupled in central Tibet and decoupled in Yunnan, but the seismic data used by them was insufficient for characterizing the implied transition in any detail. Finally, shear wave splitting measurements at an array north of the eastern Himalayan syntaxis (Fig. 1, pink dots) are consistent with crust-mantle coupling in much of eastern Tibet [24].

We report measurements of shear wave splitting at a temporary seismograph array deployed in Sichuan and Yunnan provinces (Fig. 1, blue dots). Because our study region is located in proximity to the presumed transition between the deformation regime of Tibet and that of Yunnan and south China [23], our data may yield important insight into the style of deformation in eastern Tibet. The region's oblique position to the direction of convergence may enhance three-dimensional processes,

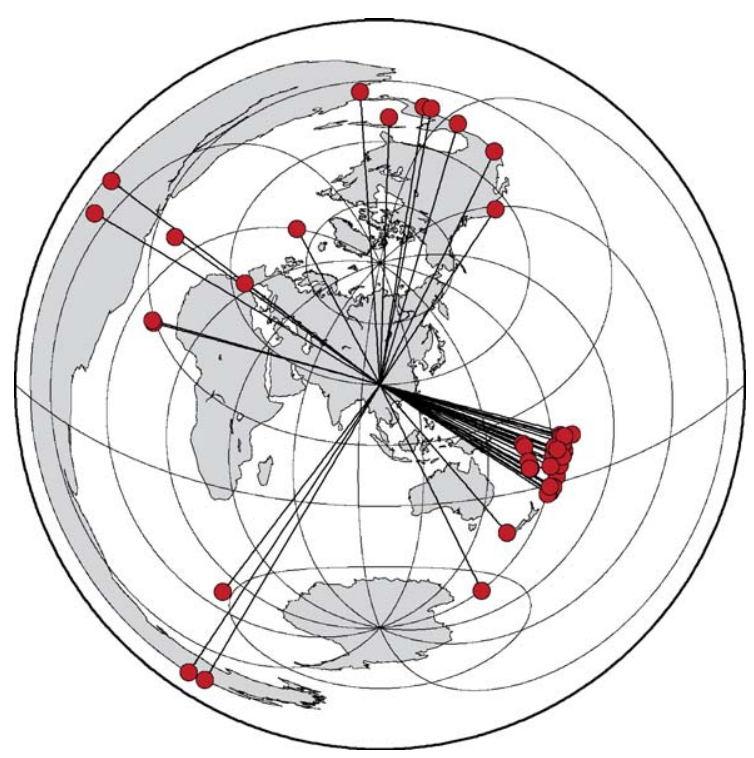

Fig. 2. Epicenters of events used in the study (red dots). We use a total of 48 events of magnitude 5.7 and above.

which might be harder to detect in the center of the plateau. Moreover, the unique structural features of eastern Tibet, specifically the abundance of strike-slip faulting, provide us with a range of surface observables that can be used to test proposed models.

Our analysis provides strong evidence for anisotropy and shows that the source of the inferred anisotropy is most likely located between 60 and $160 \mathrm{~km}$ depth (that is, in the lower crust and the continental upper mantle), that the inferred orientation of strain in this depth range differs from structural trends observed at the surface, particularly on the SE flank of the plateau in Yunnan province, and that there is a distinct change in anisotropy across the array from north-south orientations in the north to east-west in the south. The latter may present evidence for a profound transition in lithosphere deformation regime, which may have important implications for our understanding of the geotectonic evolution of the Tibetan plateau.

\section{Data and methods}

The data used here were recorded by a seismograph array operated by MIT and the Chengdu Institute of Geology and Mineral Resources (CIGMR) between September 2003 and October 2004. The array consisted of 25 broadband seismometers (20 STS2 +5 Güralp 3ESP) from the IRIS-PASSCAL pool, deployed between latitudes $24^{\circ} \mathrm{N}-32^{\circ} \mathrm{N}$ and longitudes $99^{\circ} \mathrm{E}-$ $101^{\circ} \mathrm{E}$ (Fig. 1). We also used data from the China 
Digital Seismograph Network (CDSN) station KMI, located in Kunming, Yunnan Province. In operation since 1992, and located within our temporary array, $\mathrm{KMI}$ is an important source of data and an ideal reference for the measurements made from our array. All records were band-pass filtered between corner frequencies of 0.02 and $0.15 \mathrm{~Hz}$, but the dominant period of the SKS and SKKS phases used is 10-15 s.

With a deployment period of only 13 months, our array recorded SKS and SKKS data from relatively narrow ranges of back azimuth. Furthermore, most of the sources are at an epicentral distance from which these core phases arrive within a time window shorter than the dominant period $(10-15 \mathrm{~s})$, which makes the signal too complex for measuring splitting with the methods used here. To increase the number of splitting measurements we also considered direct $\mathrm{S}$ arrivals from events that are sufficiently deep so that source-side anisotropy can reasonably be ignored. There are several regions in the appropriate distance for such phases, including the deep seismicity beneath the northwest Pacific island arcs, but none of them provided highquality splitting measurements. Therefore, no direct $\mathrm{S}$ data were used in the results presented in this paper.

Close to 3000 SKS and SKKS phase arrivals from $\sim 300$ teleseismic events $\left(\Delta=85^{\circ}-180^{\circ}\right)$ and a bodywave magnitude greater than 5.7 were recorded during the period of deployment. From these, close to 250 records from a total of 48 events were selected through visual inspection based on their signal-to-noise ratio and waveform clarity. A full list of the events used in this study is given in S1 (Electronic supplement), and Fig. 2 depicts their locations. We used the cross-correlation method [e.g. 25,26] and the multi-channel method [27] to calculate the splitting parameters, that is, the azimuth of the fast polarization direction $\phi$ and the delay time between the split phase arrivals, $\delta t$.

\subsection{The cross-correlation method}

A shear wave traveling through an anisotropic medium splits into orthogonally polarized fast and slow components. The cross-correlation method attempts to maximize the similarity in pulse shapes of these two components, which should ideally be identical, one delayed with respect to the other. Following [26], we estimate errors for individual records assuming stochastic uncorrelated noise and applying a statistical $F$-test. With the individual measurements thus obtained, we perform a grid search over possible values for $\phi$ and $\delta t$ to find the values that maximize the cross-correlation [25]. We search over a range of $\phi$ from 0 to $180^{\circ}$ and $\delta t$ between 0.1 to $3 \mathrm{~s}$ to find a $(\phi, \delta t)$ that produces the smallest root-mean-square misfit to the individual measurements. We estimate the error of the best fitting parameters using the width of the minimal misfit region in the grid search. For several stations the cross-correlation measurements varied widely and estimating an average fast direction was difficult. For the stations presented we estimate that the error in the average $\phi$ is $\pm 20^{\circ}$ and the error in $\delta t$ is $\pm 0.2 \mathrm{~s}$.

\subsection{The multi-channel method}

The technique developed by Chevrot [27] simultaneously utilizes phase arrivals from different backazimuths. The amplitude of the transverse component for records with various incoming polarizations is measured, and the azimuthal variation is compared with the predicted variation for an assumed anisotropic medium. Provided that a broad range of incoming polarizations is available, this method is convenient to use with phases of known polarization, such as the core-refracted SKS and SKKS. For a vertically incident shear wave traveling through a single horizontal layer of transverse anisotropy, and under the condition that $\delta t$ is small compared to the dominant period of the signal, the radial $(R)$ and transverse $(T)$ time series are given by the following expressions:

$$
\begin{aligned}
& R(t)=w(t) \\
& T(t)=-\frac{1}{2} \delta t \sin (2 \beta)=\dot{w}(t),
\end{aligned}
$$

where $w(t)$ is the original waveform of the pulse, $\dot{\mathrm{w}}(t)$ is the time derivative of $w(t)$, and $\beta$ is the angle between the fast direction $\phi$ and the initial polarization of the pulse. The splitting parameters can, therefore, be found by searching for the best fitting $\sin (2 \theta)$ curve to the set of measured splitting intensities. We calculate the error of individual splitting intensity measurements using the correlation between the transverse component and the time derivative of the radial component, as described in the appendix to [27]. The reliability of the splitting parameters estimated for each station depends strongly on the azimuthal distribution of the records used, and poor coverage may introduce a large error or hinder the estimation of the final parameters.

\section{Results}

\subsection{Splitting parameters (for a single-layer model)}

Measurements obtained from individual records using the cross-correlation method are included in S2 
(Electronic Supplement). As representative examples for the analysis using both the cross-correlation method and the multi-channel method, we describe here the results for stations MC04 and MC08. For station MC04 location at $\left(30.055^{\circ} \mathrm{N}, 101.48^{\circ} \mathrm{E}\right)$ at the easternmost margin of the Tibetan plateau - the cross-correlation method gives $76^{\circ}$ and $0.9 \mathrm{~s}$, and the multi-channel method gives $86^{\circ}$ and $1.16 \mathrm{~s}$, so these measurements agree within the errors of $\pm 20^{\circ}$ and $\pm 0.2 \mathrm{~s}$ (see Fig. $3 \mathrm{~A}$, B). For station $M C 08$ - located at $\left(28.99^{\circ} \mathrm{N}, 101.51^{\circ} \mathrm{E}\right)$ in the central part of the array - the cross-correlation method yielded a rather wide range of fast directions and delay times (Fig. 3E, F and S2). The multi-channel fit is better constrained, however, and hence this is the value illustrated in our maps and used in further discussion. For the stations in Fig. 3, as well as for many of the other stations, the FPDs measured with the cross-correlation method varied with back-azimuth. At stations $M C 19$ and MC20 not enough records showed measurable splitting due to a low signal-to-noise ratio, and hence no results are reported for them.

The average splitting parameters that best fit the data are listed in S3 (electronic supplement) and depicted in Figs. 1 and 4. Fig. 4A shows rose diagrams (angular

\section{$\mathrm{MCO} 4$}

A

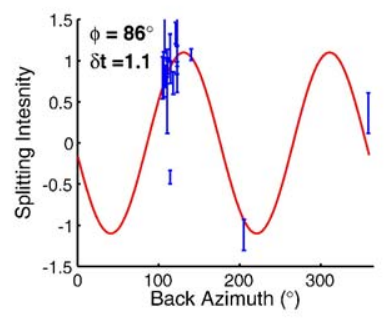

$B$

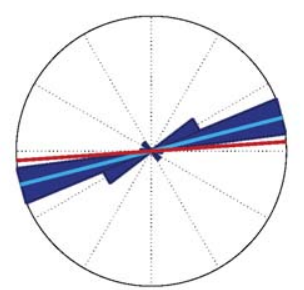

C

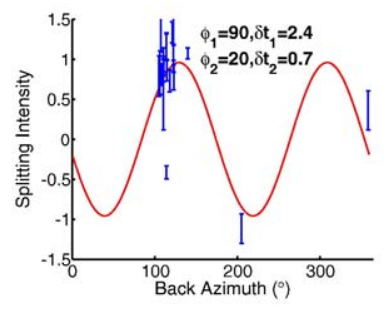

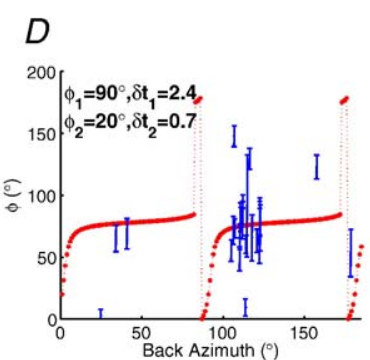

\section{MC08}

E

$F$

G
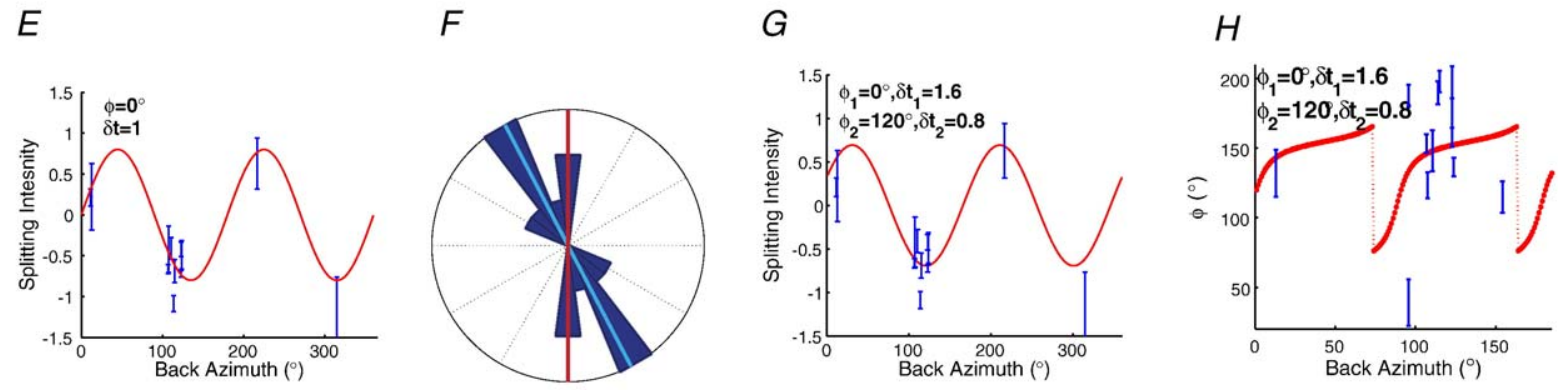

\section{$M C 13$}

I

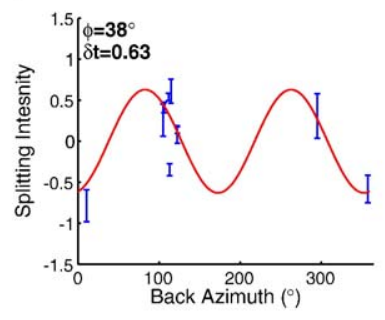

$J$

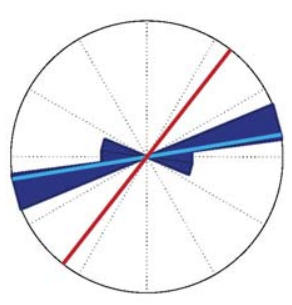

$K$

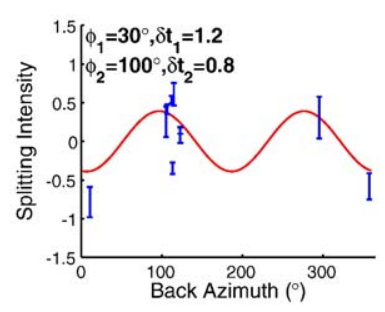

L

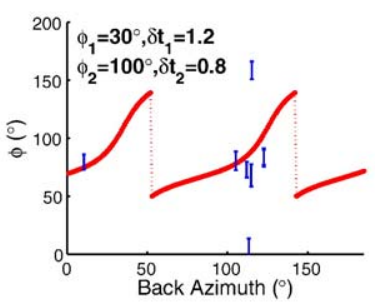

Fig. 3. Results for station MC04, MC08, and MC13. Shown are $2 \sigma$ error bars. From the left: A, E, I — splitting intensity measurements from the multi-channel method (blue), with the red curve the fit assuming a single layer of anisotropy; B, F, J - rose diagram of FPD measurements from the cross-correlation method (blue), with mean direction indicated in cyan; C, G, K - splitting intensity measurements, with a fit based on a double layer of anisotropy; $\phi_{1}, \delta t_{1}$ are splitting parameters for the bottom model layer, sampled first, and $\phi_{2}, \delta t_{2}$ are the splitting parameters for the model top layer, sampled second; D, H, L — measured (using the cross-correlation method) fast directions vs. back-azimuth (blue) and the predicted fast direction assuming a double layer model (red). 

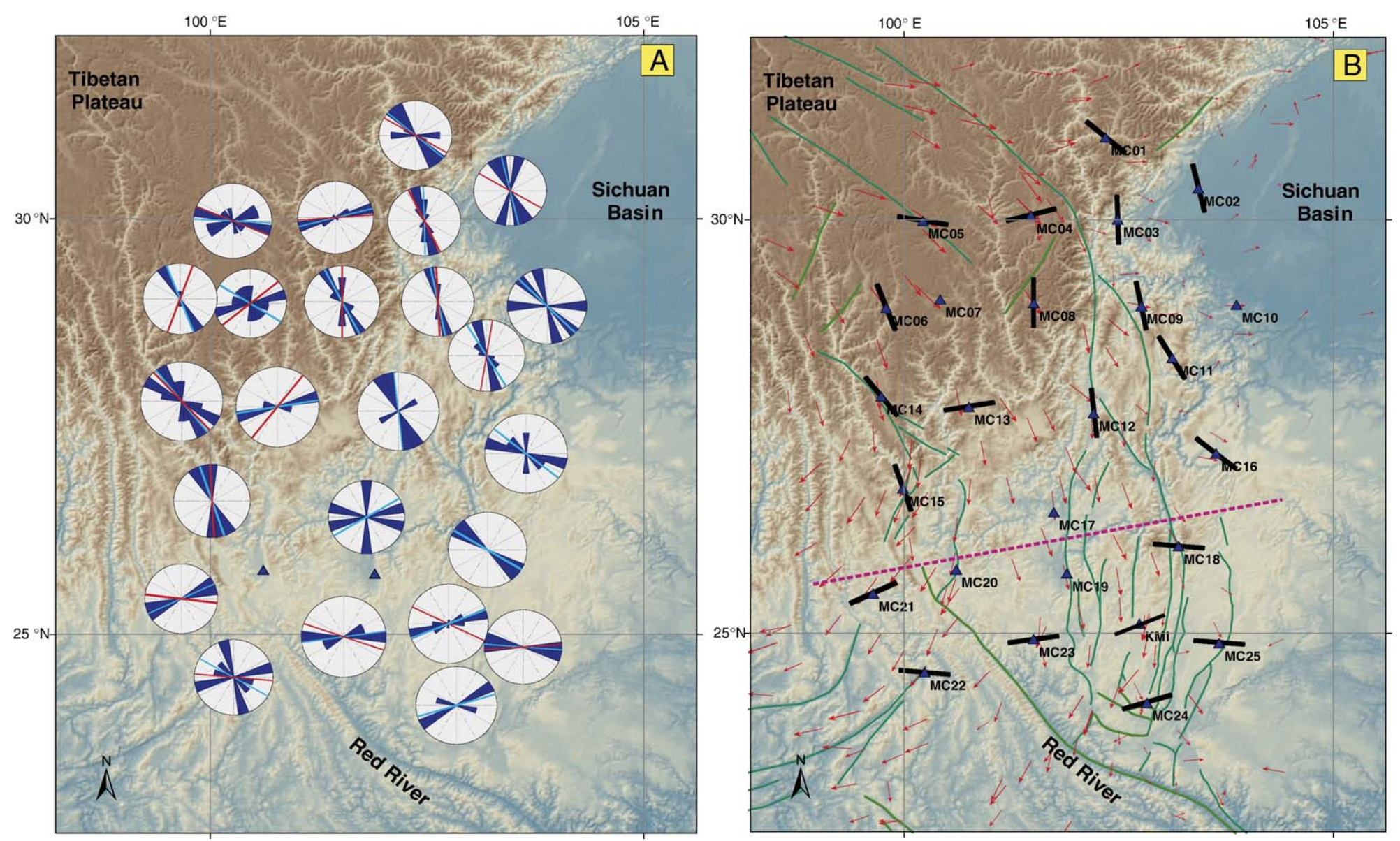

Fig. 4. Splitting measurements in eastern Tibet (assuming a single layer of anisotropy). (A) For each station, we show an angular histogram of the measurements obtained using the cross-correlation method (blue). Cyan lines show the angular average. Where applicable, red lines in the histograms give the fast direction obtained using the multi-channel method; (B) Average fast directions for wellconstrained stations (black lines). All fast direction lines are drawn at equal length. Red arrows denote surface displacement vectors from [6] and [7]. Green lines show the major regional strike-slip faults. The purple dashed line in panel B marks the estimated transition between the northern region and the southern region. 
histograms) of the fast polarization directions (FPDs) calculated by the cross-correlation method, as well as the estimate of the average fast direction under each of the stations.

For stations at which we were able to estimate splitting parameters with the multi-channel method, those measurements are also indicated. Fig. 4B summarizes the best-fitting FPDs for stations that are well-constrained, along with major regional faults and surface displacement field measured by GPS. As can be seen from Fig. 4A, at six stations both methods yield good measurements, but the FPDs from the two methods differ by $25^{\circ}$ or more. We note that for stations MC05, MC08, MC22, and $M C 25$ we plot in Fig. 4B the splitting parameters obtained by the multi-channel method.

Fig. 4 reveals a complicated geographical pattern of fast directions. Despite the scatter at individual stations, the measurements reveal a conspicuous transition from mostly north-south oriented fast directions in the northern part of the array (Figs. 4 and 5A) to fast directions oriented mostly east-west in the southern part of the array (Figs. 4 and 5B). In addition to the average values presented in Figs. 4 and 5, the difference in splitting between the north and the south can also be illustrated by measurements of splitting at individual stations. In Fig. 6A, B we show examples for the analysis of arrivals from the same event in Tonga recorded at two stations located at different parts of the array. Additionally, Fig. $6 \mathrm{C}$ shows another arrival from an event in the Tonga region recorded at $M C 15$ and Fig. 6D displays an example of an arrival with a different incoming polarization from an event in Chile.

\subsection{Evidence for multiple layers of anisotropy?}

It has been suggested $[28,29]$ that the kind of variability observed in some stations of our array (Fig. 4) may result from an anisotropic structure that is more complex than the single layer assumed initially. Also the relationship between the FPD pattern and the main trends in the surface geology and in the GPS displacement field (Fig. 4) suggests significant complexity. Therefore, we tested whether a model consisting of two horizontal anisotropic layers could explain the data better. Since the two analysis methods described above assume a single anisotropic layer with a horizontal fast axis, some modifications are necessary when a doublelayer structure is considered.

For a two-layer model, the splitting parameters measured with the cross-correlation method are expected to depend strongly on the initial polarization of the waves [30]. For a vertical incidence the "apparent" splitting
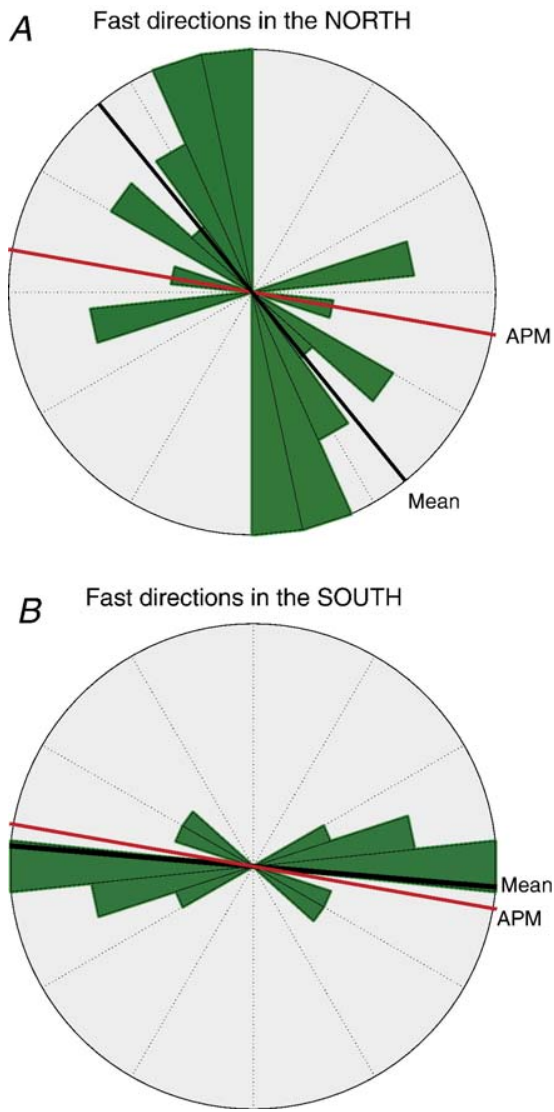

Fig. 5. Rose diagram for the average FPDs of the stations in the northern and central parts of the array (A) and in the south (B). Average FPDs for stations $M C 01$ through $M C 17$ are included in the northern and central region. Average FPDs for stations MC18 and MC21 through MC25 and $\mathrm{KMI}$ are included in the southern region. The average direction for each region is indicated in black, and the NUVEL-1 absolute plate motion (APM) direction is indicated in red. These summary diagrams demonstrate that there is a transition from a NNW-SSE trend in the north and center to an $\mathrm{E}-\mathrm{W}$ trend in the south.

parameters vary with back-azimuth with a $\pi / 2$ periodicity [e.g. 31]. In this study we use the algorithm given in [32] for predicting apparent splitting parameters for a given double-layer model. We try to find a set of two pairs of splitting parameters $\left[\left(\phi_{1}, \delta t_{1}\right),\left(\phi_{2}, \delta t_{2}\right)\right]$, for the bottom and top layers respectively, that would give the best fit to the measured apparent splitting parameters. For the multi-channel method the splitting intensity measured at the surface is the integration of the splitting intensity caused by each of the layers through which the wave travels. Mathematically this is equivalent to a summation of sinusoids, which produces a sinusoid with a different phase and amplitude. With this method it is, therefore, difficult to discriminate visually between a 
A Station MC06 - event 2004-107 Original Particle motion

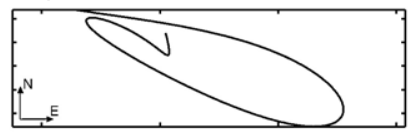

Original Horizontal Records

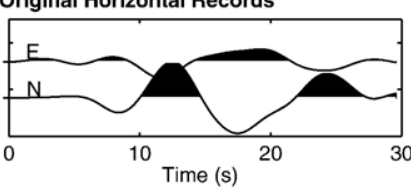

Corrected Particle motion

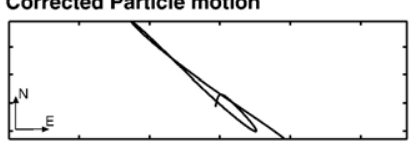

Corrected Horizontal Records

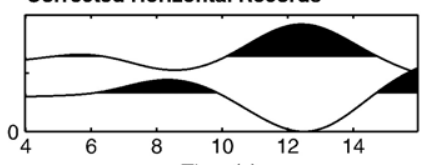

Error surfaces

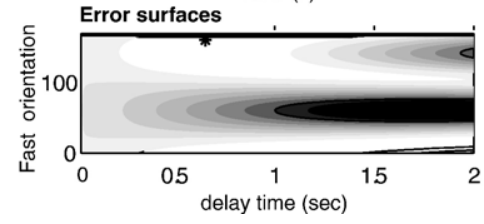

$B$

Station MC21 - event 2004-107
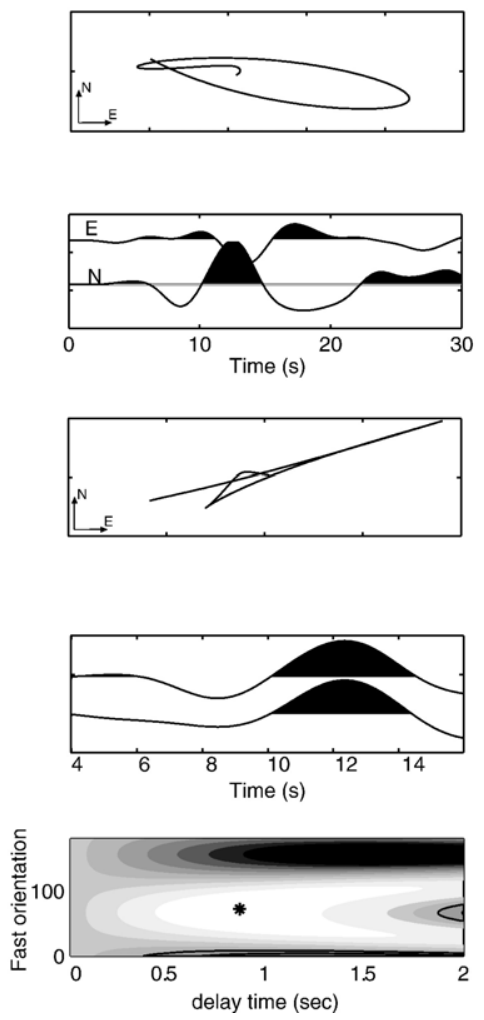

$C_{\text {Station MC15 - event 2004-025 }}$
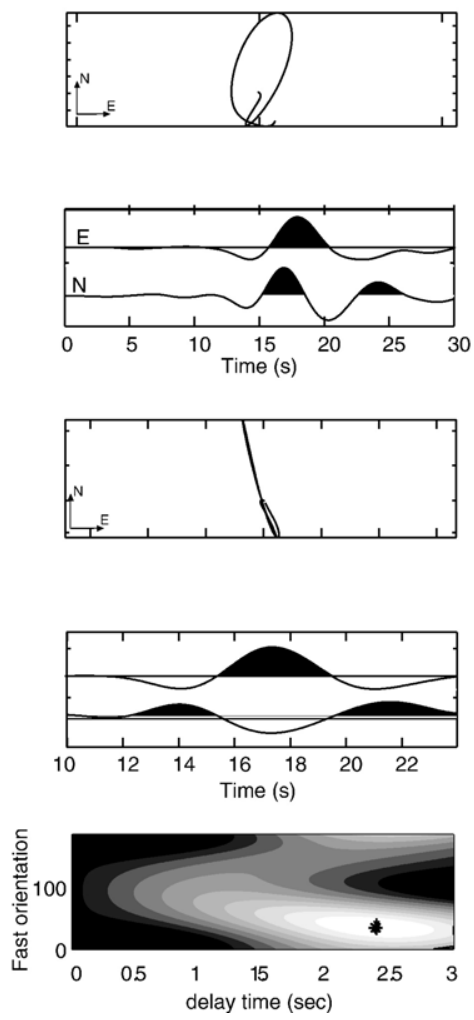

$D$ Station MC05 - event 2004-124
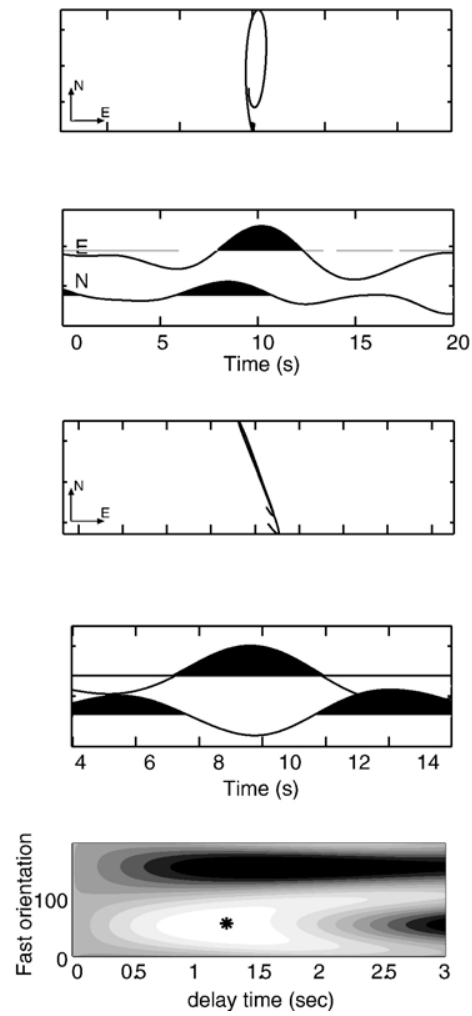

Fig. 6. Examples for records analyzed using the cross-correlation method. The same seismic event is shown for two stations from different regions of the array - station MC06 (A) is located in the north, and station MC21 (B) is in the south. Events 107 and 025, shown in panels (A)-(C), both occurred in the Tonga-Kermadec region, and event 124, shown in panel (D), occurred in Chile. From the top: particle motion before correcting for the splitting; original horizontal records; particle motion after correction; corrected (rotated and time-shifted) horizontal records; contour plot of the error surface for the obtained delay time (horizontal axis) and fast direction (vertical axis). The preferred solution for the splitting parameters is marked by a black asterisk 
case of multiple horizontal layers or a single layer. We performed a grid search at each station over a range of fast directions and delay times for a two layer model, with a step size of $10^{\circ}$ for directions and $0.1 \mathrm{~s}$ for delay time. The misfit was calculated using the root-meansquare of the difference between the data and the model predictions, weighted by the individual errors.

Because of the limited azimuthal coverage, constraining a two-layer structure is difficult. While the FPDs of the lower model layer could in most cases be determined within $\pm 10^{\circ}$, the upper layer was mostly unconstrained. Fig. 3C, D and G, H display results for stations MC04 and MC08. We find that, in general, a double-layer model does not significantly improve the fit to the data. In some cases, however, using a doublelayer model reduces the disagreement between the results from analysis methods, which we regard as an improvement. At station $M C 13$, for instance, whereas the single-layer estimates of the two methods differ by $42^{\circ}$ (Fig. 3I, J), the double-layer solution is within error for both of them (Fig. 3K, L). We conclude that while a two-layer model may be consistent with our observations, the data considered here do not require it.

\section{Discussion}

One of the main results of our analysis is the north-tosouth transition in the orientation of the FPDs (Figs. 4 and 5). Exceptions to this trend, such as stations $M C 04$, $M C 05$, and $M C 13$, may be affected by local, nearstation structure. This transition connects the trends inferred from studies in neighboring areas; Sol et al. [24] measured NW-SE trending FPDs to the northwest of our array (Fig. 1, pink dots), whereas Flesch et al. [23] report east-west FPDs for Yunnan province, south of our study region (Fig. 1, orange dots). The transition occurs near $26-27^{\circ} \mathrm{N}$ over a horizontal distance of several hundreds of kilometers. In this region seismic tomography reveals significant heterogeneity in the deep lithosphere and uppermost mantle $[33,34]$.

\subsection{Arguments for an upper mantle source of the splitting signal}

An inherent limitation of using core-refracted waves such as $S K S$ and $S K K S$ to study anisotropy is the pathintegration of the signal, which makes it difficult to determine the depth of anisotropy. However, the following observations give some insight about the depth of the anisotropy. First, at many stations the inferred splitting time is $>0.6 \mathrm{~s}$, which is generally considered too large to be all of crustal origin [35]. However, with a crustal thickness of 50-70 km [36] this by itself is not a strong argument for a sub-crustal origin. Second, the approximate width of the Fresnel zones of the recorded phases help estimate the maximum and minimum depth of the anisotropy. For example, the neighboring stations $M C 01$ and $M C 03$, separated by $110 \mathrm{~km}$, show different splitting both on average and for multiple events recorded at both stations. This suggests that the anisotropy has a fairly shallow source. Using a quarter-wavelength approximation for the Fresnel zone width [37] and considering a dominant period of $10 \mathrm{~s}$, we estimate that most of the anisotropic signal probably originates above $160 \mathrm{~km}$ depth. On the other hand, the comparison of the splitting of two events from opposing back-azimuths recorded at a single station (MC11 for instance) suggests a minimum depth of the anisotropy of $65 \mathrm{~km}$.

In the northern and eastern part of the array the FPDs display much spatial variability, and in much of the study region the FPDs are quite different from the main trends in the surface geology and in the GPS displacement field (Fig. 4B). The relationship of the inferred anisotropy with independent observations suggests that it is unlikely that it is produced by processes in the crust, which are presumably represented by the regional strike-slip faults and the surface stress field. Alignment of minerals in the crust by strong shearing along strike-slip faults would align the FPDs with the faults. When we examine the correlation between the FPDs and the strike of faults we find that it is rather poor (Fig. 7A), although visual inspection suggests that it is better in the north than in the south of the array. Alternatively, ductile flow in the lower crust would align crustal minerals such as mica and produce a fabric with slow axis of symmetry that is aligned with the flow. In that case the FPDs should have been perpendicular to the direction of shearing [e.g. 38,39]. A different mechanism for creating anisotropy in the crust is the alignment of micro-cracks. The response of micro-cracks to the stress field in the crust results in the alignment of FPDs with the direction of the most compressive stress $\sigma_{\mathrm{SH}}$ [e.g. 40,41]. Fig. 7B indicates that, in general, the FPDs do not correlate with the direction of $\sigma_{\mathrm{SH}}$ as inferred from the World Stress Map [42]. We therefore conclude that the source for the observed anisotropy is unlikely to be in the crust.

\subsection{Anisotropy in Yunnan province and near the Red River Fault}

The fast directions just north of the Red River fault zone are particularly intriguing, as they suggest that the uppermost mantle is deforming in east-west direction, in contrast with models that suggest that near-surface 
A

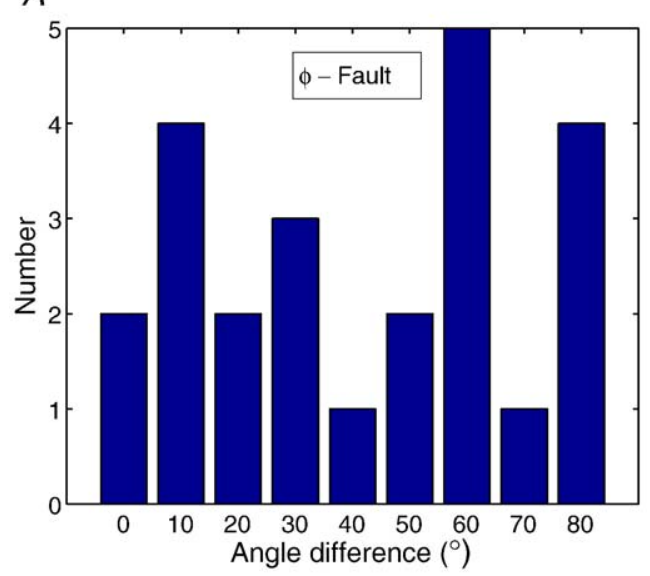

$B$

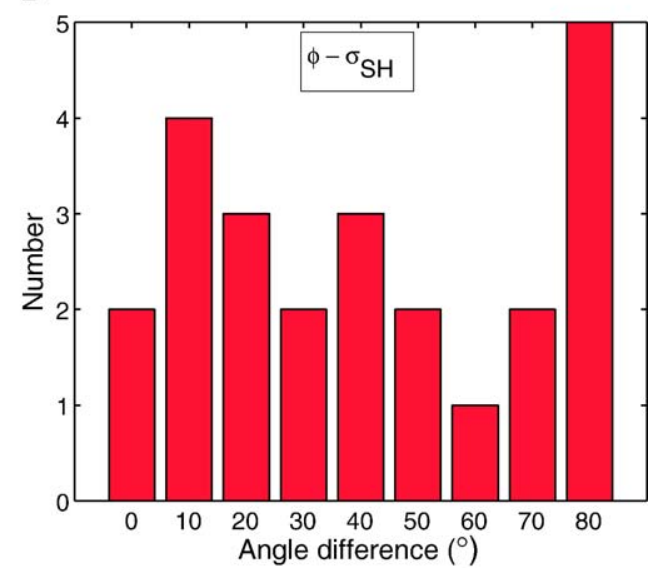

Fig. 7. Testing the correlation of fast polarization directions with surface features - Histograms of angular difference between measured FPDs and: (A) the nearest fault strike and (B) the local most compressive stress direction $\sigma_{\mathrm{SH}}$ as estimated from the World Stress Map [42]. No fast directions were calculated for MC19 and $M C 20$, due to insufficient data.

deformation is in north-south direction and continuous across the fault [e.g. 43]. The fast polarization directions in the south (Fig. 5B) are - within error - parallel to the absolute plate motion (APM) in the region, which is $\sim \mathrm{N} 100^{\circ}$ E according to NUVEL-1 [44], and may be related to mantle shearing caused by the plate motion. The situation in this part of the array may, however, be more ambiguous than it appears at first glance.

Strike-slip faults are the most prominent structural features in this part of the array. In general, the strikes of these shear zones are approximately north-south, which is almost perpendicular to the direction of the anisotropic fabric in the upper mantle as inferred from shear wave splitting. It appears, however, that this area is actually undergoing rather significant east-west extension [e.g.
$45,46]$. The driving force for this transtensional tectonic regime is not well-known. It could be related to distant subduction processes, including slab rollback, to the west (the Indo-Burma system) and south-east (e.g., Philippines and Indonesia). Alternatively, it could reflect east-west strain in the crust as it spreads out when it slides off the flanks of the plateau. The latter would be consistent with the divergence in the directions of nearsurface displacement inferred from GPS measurements. If the southward moving crust is indeed extending in east-west direction, then the fast directions we observe in the south could, in fact, be consistent with surface processes, even if there is substantial differential motion (and, by implication, a sufficient level of mechanical decoupling) between the upper crust and the uppermost mantle. However, the crust contribution to the splitting signal is probably minor (see previous section) and an explanation must still be sought for the dramatic southward change in the deformation of the uppermost mantle revealed by our splitting measurements.

\subsection{Implications for lithosphere mechanics}

The observations presented here give a first-order estimation of anisotropy in eastern Tibet and have implications for our understanding of lithospheric deformation, including, perhaps, the level of crust and mantle coupling in the region. The splitting measurements suggest that the upper-most mantle is the most likely source of the anisotropy measured here, and that its deformation geometry is generally different from that in the crust. The anisotropy may be either a result of recent deformation, representing present-day processes, or a fossilized fabric resulting from an older process. If we take the anisotropy to represent the current deformation regime in the uppermost mantle beneath eastern Tibet, then our observations and inferences are suggestive of mechanical decoupling of the upper crust from the mantle, in particular in the south. We stress that in the northern region within the plateau such decoupling may not be required to explain the observations discussed here.

Irrespective of the level of crust-mantle decoupling, our results suggest a profound change in deformation regime. Further studies are needed to establish the nature of transition in more detail, but we postulate that it reflects a transition from collision controlled deformation in the north and northwest, including the Tibetan plateau itself, to deformation influenced by other forces further to the south. The vertical resolution, limited when using teleseismic shear wave splitting, may be improved by using anisotropic receiver functions or through the analysis of splitting in $(\mathrm{P}-\mathrm{S})$ conversions at 
the Moho or at intra-crustal interfaces. Unfortunately, our array may not provide sufficient data for such detailed analysis. A more promising approach toward constraining the lateral variations of anisotropy would be the tomographic inversion of relatively short-period surface wave dispersion [47].

\section{Summary}

We have used shear wave splitting to investigate seismic anisotropy and deformation in Eastern Tibet. Even though there is significant scatter, the measurements based on the assumption of a single layer of anisotropy reveal a conspicuous change in the fast direction pattern from mostly north-south orientations in the north to mostly east-west in the south. Based on the magnitude of delay times, the size of Fresnel zones, and the poor correlation between directions of fast polarization on the one hand, and near-surface geology and geodetically inferred surface displacement patterns, on the other hand, we argue that the anisotropy is most likely located in the lower part of the thick crust and in uppermost mantle.

Distinguishing among different models of lithospheric rheology is difficult based solely on shear wave splitting measurements. In the northern part of the array the data may be consistent both with coherent deformation of the shallow crust and the uppermost mantle and with mechanical decoupling between them. However, in Yunnan province and the southeastern flank of the Tibetan plateau, the observations strongly suggest that the deformation patterns of the upper crust and mantle are different, and hence that there is significant mechanical decoupling between them. The observed difference between the northern and southern parts of our study region may thus reflect lateral variations in lithospheric rheology. It could also mark a change in the tectonic regime, with the impact of the collision weakening and that of far-field forces related to distant subduction processes strengthening as we go southward. The transition occurs over a region of significant tomographically inferred mantle heterogeneity, which suggests that sub-lithospheric structures and processes may influence regional near-surface deformation. If corroborated by further study, this transition should be accounted for in geodynamical models for the evolution of the Tibetan plateau.

\section{Acknowledgements}

We thank Prof. Chen and staff at the Chengdu Institute for Geology and Mineral Resources for their help and support. We benefited from discussions with Clark Burchfiel, Leigh Royden, Christopher StudnickiGizbert, Kristen Cook, Anne Meltzer, Stephan Sol, Paul Tapponnier, Brad Hager and Francis Wu. Comments by Paul Silver on an earlier version of this paper were greatly appreciated. We are grateful for the insightful reviews by Vadim Levin and an anonymous reviewer, which helped us improve this manuscript. The research presented here was supported by NSF under grants EAR-0337697, EAR-0409564 and CD-6892042.

\section{Appendix A. Supplementary data}

Supplementary data associated with this article can be found, in the online version, at doi:10.1016/j.epsl. 2006.09.018.

\section{References}

[1] P. Molnar, P. Tapponnier, Active tectonics of Tibet, J. Geophys. Res. 83 (1978) 5361-5376.

[2] P. Molnar, P. Tapponnier, Cenozoic Tectonics of Asia: effects of a continental collision, Science 189 (1975) 419-426.

[3] P. England, G. Houseman, Finite strain calculations of continental deformation 2. Comparison with the India-Asia collision zone, J. Geophys. Res. 91 (10) (1986) 3664-3676.

[4] B.C. Burchfiel, Z. Chen, Y. Liu, L.H. Royden, Tectonics of the Longmenshan and adjacent regions, Int. Geol. Rev. 37 (1995) 661-735.

[5] L. Royden, B.C. Burchfiel, R.W. King, Z. Chen, F. Shen, Y. Liu, Surface deformation and lower crustal flow in eastern Tibet, Science 276 (1997) 788-790.

[6] Z. Chen, B.C. Burchfiel, Y. Liu, R.W. King, L.H. Royden, W. Tang, E. Wang, J. Zhao, X. Zhang, Global Positioning System measurements from eastern Tibet and their implications for India/ Eurasia intercontinental deformation, J. Geophys. Res. 105 (2000) 16215-16228.

[7] P.Z. Zhang, Z. Shen, M. Wang, G.W., R. Burgmann, P. Molnar, Z. Niu, J. Sun, J. Wu, H. Sun, X. You, Continuous deformation of the Tibetan Plateau from global positioning data, Geology 32 (2004) 809-812.

[8] Z. Zhang, S.I. Karato, Lattice preferred orientation in olivine aggregates deformed in simple shear, Nature 375 (1995) 774-777.

[9] A. Tommasi, D. Mainprice, G. Canova, Y. Chastel, Viscoplastic self-consistent and equilibrium-based modeling of olivine lattice preferred orientations: implications for the upper mantle seismic anisotropy, J. Geophys. Res. 105 (2000) 7893-7908.

[10] É. Kaminski, N.M. Ribe, A kinematic model for recrystallization and texture development in olivine polycrystals, Earth Planet. Sci. Lett. 189 (2001) 253-267.

[11] J.-P. Montagner, H.-C. Nataf, A simple method for inverting the azimuthal anisotropy of surface waves, J. Geophys. Res. 91 (10) (1986) 511-520.

[12] F.J. Simons, R.D. van der Hilst, J.P. Jean-Paul Montagner, A. Zielhuis, Multimode Rayleigh wave inversion for heterogeneity and azimuthal anisotropy of the Australian upper mantle, Geophys. J. Int. (2001) 738-754. 
[13] V. Levin, J. Park, P-SH conversions in layered media with hexagonally symmetric anisotropy: a cookbook, Pure Appl. Geophys. 151 (1998) 669-697.

[14] H. Hess, Seismic anisotropy of the uppermost mantle under oceans, Nature 203 (4945) (1964) 629-631.

[15] D.E. McNamara, W.R. Walter, T.J. Owens, C.J. Ammon, Upper mantle velocity structure beneath the Tibetan Plateau from Pn travel time tomography, J. Geophys. Res. 102 (1997) 493-506.

[16] P.G. Silver, W.W. Chan, Shear wave splitting and subcontinental mantle deformation, J. Geophys. Res. 96 (15) (1991) $16429-16454$

[17] D.E. McNamara, T.J. Owens, P.G. Silver, F.T. Wu, Shear wave anisotropy beneath the Tibetan Plateau, J. Geophys. Res. 99 (1994) 13655-13665.

[18] W.E. Holt, N. Chamot-Rooke, X.L. Pichon, A.J. Haines, B. Shen-Tu, J. Ren, Velocity field in Asia inferred from Quaternary fault slip rates and Global Positioning System observations, J. Geophys. Res. 105 (2000) 19185-19210.

[19] D. Griot, J. Montagner, P. Tapponnier, Confrontation of mantle seismic anisotropy with two extreme models of strain, in Central Asia, Geophys. Res. Lett. 25 (1998) 1447-1450.

[20] N.M. Shapiro, M.H. Ritzwoller, P. Molnar, V. Levin, Thinning and flow of Tibetan crust constrained by seismic anisotropy, Science 305 (2004) 233-236.

[21] H.F. Sherrington, G. Zandt, A. Frederiksen, Crustal fabric in the Tibetan Plateau based on waveform inversions for seismic anisotropy parameters, J. Geophys. Res. 109 (2004) B2312.

[22] A.A. Ozacar, G. Zandt, Crustal seismic anisotropy in central Tibet: Implications for deformational style and flow in the crust, Geophys. Res. Lett. 31.

[23] L.M. Flesch, W.E. Holt, P.G. Silver, M. Stephenson, C.-Y. Wang, W.W. Chan, Constraining the extent of crust-mantle coupling in central Asia using GPS, geologic, and shear wave splitting data [rapid communication], Earth Planet. Sci. Lett. 238 (2005) $248-268$

[24] S. Sol, A. Meltzer, B. Zurek, P. Zeitler, X. Zhang, Clockwise rotation of upper-mantle strain and crust-mantle coupling beneath the eastern syntaxis Tibet, Eos Trans., AGU Fall Meeting Abstracts, vol. 86 (52), 2005, T41A-1280.

[25] Y. Fukao, Evidence from core-reflected shear waves for anisotropy in the Earth's mantle, Nature 309 (1984) 695-698.

[26] V. Levin, W. Menke, J. Park, Shear-wave splitting in the Appalacians and the Urals: a case for multilayered anisotropy, J. Geophys. Res. 104 (1999) 17975-17993.

[27] S. Chevrot, Multichannel analysis of shear wave splitting, J. Geophys. Res. 105 (2000) 21579-21590.

[28] V. Levin, D. Droznin, J. Park, E. Gordeev, Detailed mapping of seismic anisotropy with local shear waves in southeastern Kamchatka, Geophys. J. Int. 158 (2004) 1009-1023.

[29] M.D. Long, R.D. van der Hilst, Upper mantle anisotropy beneath Japan from shear wave splitting, Phys. Earth Planet. Inter. 151 (2005) 206-222.

[30] P.G. Silver, M.K. Savage, The interpretation of shear-wave splitting parameters in the presence of two anisotropic layers, Geophys. J. Int. 119 (1994) 949-963.

[31] G. Rumpker, P.G. Silver, Apparent shear-wave splitting parameters in the presence of vertically varying anisotropy, Geophys. J. Int. 135 (1998) 790-800

[32] M.K. Savage, P.G. Silver, Mantle deformation and tectonics: constraints from seismic anisotropy in the western United States, Phys. Earth Planet. Inter. 78 (1993) 207-227.
[33] C. Li, R.D. van der Hilst, A. Meltzer, P-wave velocity variation in the upper mantle beneath Tibetan Plateau, Eos Trans., AGU Fall Meeting Abstracts, vol. 86 (52), 2005, T52-08.

[34] C. Li, R.D. van der Hilst, M.N. Toksöz, Constraining P-wave velocity variations in the upper mantle beneath Southeast Asia, Phys. Earth Planet. Inter. 154 (2006) 180-195.

[35] G. Barruol, D. Mainprice, A quantitative evaluation of the contribution of crustal rocks to the shear-wave splitting of teleseismic SKS waves, Phys. Earth Planet. Inter. 78 (1993) 281-300.

[36] A. Bhaskar, B. Savage, P. Silver, Crustal structure beneath the southeastern Tibetan plateau and Yunnan Province using teleseismic data, Eos Trans., AGU Fall Meeting Abstracts, vol. 86 (52), 2005, A1282.

[37] D. Alsina, R. Snieder, Small-scale sublithospheric continental mantle deformation - constraints from SKS splitting observations, Geophys. J. Int. 123 (1995) 431-448.

[38] G. Barruol, H. Kern, Seismic anisotropy and shear-wave splitting in lower-crustal and upper-mantle rocks from the Ivrea Zoneexperimental and calculated data, Phys. Earth Planet. Inter. 95 (1996) $175-194$.

[39] N.J. Godfrey, N.I. Christensen, D.A. Okaya, Anisotropy of schists: contribution of crustal anisotropy to active source seismic experiments and shear wave splitting observations, J. Geophys. Res. 105 (2000) 27991-28008.

[40] P.C. Leary, S. Crampin, T.V. McEvilly, Seismic fracture anisotropy in the Earth's Crust: an overview, J. Geophys. Res. 95 (1990) 11105-11114.

[41] Z. Peng, Y. Ben-Zion, Systematic analysis of crustal anisotropy along the Karadere-Du"zce branch of the North Anatolian fault, Geophys. J. Int. 159 (2004) 253-274.

[42] J. Reinecker, O. Heidbach, M. Tingay, P. Connolly, B. Müller, The 2004 Release of the World Stress Map, 2004, URL www. world-stress-map.org.

[43] R.W. King, F. Shen, B.C. Burchfiel, L.H. Royden, E. Wang, Z. Chen, Y. Liu, X. Zhang, J. Zhao, Y. Li, Geodetic measurement of Crustal Motion in Southwest China, Geology 25 (1997) 179-182.

[44] C. DeMets, R.G. Gordon, D.F. Argus, S. Stein, Effect of recent revisions to the geomagnetic reversal time scale on estimates of current plate motions, Geophys. Res. Lett. 21 (1994) 2191-2194.

[45] E. Wang, B.C. Burchfiel, Interpretations of Cenozoic tectonics in the right-lateral accommodation zone between the Ailo Shan shear zone and the Eastern Hymalayan syntaxis, Int. Geol. Rev. 39 (1997) 191-219.

[46] E. Wang, B.C. Burchfiel, L.H. Royden, C. Liangzhong, C. Jishen, L. Wenxin, C. Zhiliang, Late Cenozoic XianshuiheXiaojiang, Red River and Dali Fault Systems of Southwestern Sichuan and Central Yunnan, China, Spec. Pap. - Geol. Soc. Am. 327 (1998) 188 pp.

[47] H. Yao, R.D. van der Hilst, M.V. de Hoop, Surface-wave array tomography in SE Tibet from ambient seismic noise and twostation analysis: I- phase velocity maps, Geophys. J. Int. 166 (2006) 732-744.

[48] W. Huang, J.F. Ni, F. Tilmann, D. Nelson, J. Guo, W. Zhao, J. Mechie, R. Kind, J. Saul, R. Rapine, T.M. Hearn, Seismic polarization anisotropy beneath the central Tibetan Plateau, J. Geophys. Res. 105 (2000) 27979-27990. 